\title{
Vertical variation in Vibrio community composition in Sansha Yongle Blue Hole and its ability to degrade macromolecules
}

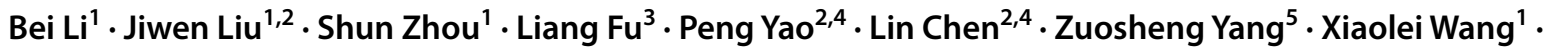 \\ Xiao-Hua Zhang ${ }^{1,2,6}$
}

Received: 16 April 2019 / Accepted: 30 July 2019 / Published online: 27 September 2019

(c) The Author(s) 2019

\begin{abstract}
With the advantages of wide distribution, fast growth, and broad metabolic spectrum to organic carbon compounds, Vibrio may play an important role in organic carbon cycling. However, the ecological roles of Vibrio in many marine environments have not been explored. Here, the world's deepest 'blue hole', the Sansha Yongle Blue Hole (SYBH) in the South China Sea, which is a geographically semi-enclosed environment featuring unique chemical characters, was investigated. The abundance, diversity and carbon source utilization capability of Vibrio were studied by quantification and high-throughput sequencing of Vibrio specific 16S rRNA genes and cultivation methods. The abundance of Vibrio in water column of the SYBH ranged from $3.78 \times 10^{4}$ to $7.35 \times 10^{6} 16 \mathrm{~S}$ rRNA gene copies $\mathrm{L}^{-1}$. Free-living Vibrio was more abundant than particle-associated Vibrio $\left(\sim 1.20 \times 10^{6}\right.$ versus $\sim 2.68 \times 10^{5}$ gene copies $\left.\mathrm{L}^{-1}\right)$, indicating that Vibrio prefers a free-living life style. The Vibrio assemblages showed clear vertical stratification and could be divided into three groups: aerobic-transition, middle anaerobic and bottom anaerobic zones. Dissolved oxygen (DO), temperature, $\mathrm{pH}$ and salinity were the main environmental factors affecting the abundance and community composition. Cultivated Vibrio demonstrated a degrading capability to various macromolecular substrates, including starch, Tween 20/40/80, DNA, gelatin, alginate, casein, chitin, lecithin, $\kappa$-carrageenan, mannan, xylan and hyaluronic acid. This suggests that Vibrio could produce a variety of highly active extracellular enzymes. Our study provides new insights into the distribution pattern and possible role in carbon cycle of Vibrio in the unique environment of a 'blue hole'.
\end{abstract}

Keywords Vibrio community · Vertical stratification · Carbon source utilization · Sansha Yongle Blue Hole

\section{Introduction}

The genus Vibrio is a group of gram-negative bacteria belonging to the Vibrionaceae family of the Gammaproteobacteria, which are usually mesophilic and heterotrophic motile rods (Thompson et al. 2004a). Vibrio species are ubiquitous in estuarine and marine habitats worldwide,

Edited by Chengchao Chen

Electronic supplementary material The online version of this article (https://doi.org/10.1007/s42995-019-00003-4) contains supplementary material, which is available to authorized users.

Bei Li and Jiwen Liu contributed equally to this work.

Xiao-Hua Zhang

xhzhang@ouc.edu.cn

Extended author information available on the last page of the article even including deep-sea hydrothermal vents and sediments at a depth of more than $6000 \mathrm{~m}$, and seawater at a depth of 10,500 $\mathrm{m}$ in the Mariana Trench (Hasan et al. 2015; Hsieh et al. 2008; Li et al. 1999; Liu et al. 2019). In addition, species within the Vibrionaceae family show two alternative niche specializations, i.e., free-living forms or attached to particles (such as biotic and abiotic surfaces) (Reen et al. 2006). Currently, the genus Vibrio contains more than 110 species, many of which are known as causative agents of foodborne related illnesses, which have a huge impact on public health and management (Lee and Raghunath 2018; Letchumanan et al. 2015; Pruzzo et al. 2005). The major pathogenic Vibrio species include Vibrio cholerae, V. parahaemolyticus and V. vulnificus (Letchumanan et al. 2016).

Despite the importance of microbially driven carbon cycling, the exact mechanisms of carbon cycling in the ocean are poorly understood. Due to wide distribution, very short replication times (as short as $\sim 10 \mathrm{~min}$ ) and an 
ability to utilize a wide range of organic carbon compounds, Vibrio, one of the best model marine heterotrophic bacterial groups, is of great value in understanding marine organic carbon cycling (Zhang et al. 2018). Vibrio spp. show distinct abilities to break down and utilize common carbon substrates via extracellular enzymes, such as chitinase (Svitil et al. 1997), protease (Venugopal and Saramma 2006), xylanase (Araki et al. 1999b), mannanase (Tamaru et al. 1995), $\kappa$-carrageenanase (Araki et al. 1999a), fucoidanase (Furukawa et al. 1992), laminarinase and alginase (Davis 1992). The production and secretion of these enzymes could provide access to abundant nutrients that are unavailable to other organisms (Mansergh and Zehr 2014; Thompson and Polz 2006). In addition, Vibrio spp. are copiotrophic bacteria that have the capacity to increase rapidly in abundance, shifting from a relatively rare component to being dominant in response to environmental perturbations and climate changes (Gilbert et al. 2012; Oberbeckmann et al. 2012; Takemura et al. 2014).

Blue holes are underwater caves, found in shallow marine and fresh waters (Whitaker and Smart 1990). Blue holes have been widely studied over decades, and have provided information on global climate change, marine ecology and carbonate geochemistry (Mylroie et al. 1995). Blue holes differ from other marine habitats in that they have little to no photosynthetic oxygen production and restricted vertical mixing, which results in anoxic or microoxic conditions. They also have further distinct biogeochemical reactions compared to other marine environments (Gonzalez et al. 2011). In many blue holes, microbial metabolism of organic matter, which might have originated from in situ bacterial primary production coupled with oxidization of inorganic sources (e.g., sulfide, ammonium and methane; Brankovits et al. 2017), leads to anoxic conditions. For example, chemoautotrophic bacteria discovered in a ground-water blue hole ecosystem in southern Romania and an anchialine cave in Yucatan Peninsula might provide sufficient organic matter to the food web (Brankovits et al. 2017; Pohlman et al. 1997; Sarbu et al. 1996). Unique microbial communities have been reported from oxic zones to anoxic zones in the Jewfish Sink of the Gulf of Mexico (Garman and Garey 2005). In this blue hole, sulfate reduction appears to be the major metabolic process in the anoxic zones, the walls of which have characteristic microbial mats, whereas bacterial activity in the oxic zones appears to be phosphate-limited (Garman and Garey 2005).

Sansha Yongle Blue Hole (SYBH, $16^{\circ} 31^{\prime} 30^{\prime \prime} \mathrm{N}$, $\left.111^{\circ} 46^{\prime} 05^{\prime \prime} \mathrm{E}\right)$, also called the Dragon Hole, is located on Yongle Atoll in the Paracel Islands of the South China Sea and is the deepest $(\sim 300 \mathrm{~m})$ blue hole in the world (Li et al. 2018). The lack of fresh water input or a subsurface connection to the sea makes SYBH an isolated and still ecosystem (Xie et al. 2019), representing a natural laboratory for the study of microbial communities. SYBH contains multiple pycnoclines, each associated with complex physicochemical profiles (Bi et al. 2018), which may strongly affect the vertical distributions of indigenous microbial communities. Research on SYBH is still at the initial stage. Although some water column chemistry data have been reported recently (Bi et al. 2018; Xie et al. 2019), little is known about the biogeochemical cycles in this blue hole.

In this study, the abundance and community structure of Vibrio population at different depths within SYBH were investigated by Vibrio-specific 16S rRNA gene highthroughput sequencing and quantitative PCR (qPCR), as well as traditional cultivation methods. The key environmental factors driving the Vibrio community changes were evaluated by statistical analysis. The organic carbon utilization characteristics of Vibrio isolates were explored through extracellular enzymatic activity experiments. A significant vertical variation of the Vibrio community in SYBH in relation to various environmental factors was discovered, and the Vibrio isolates were able to degrade a variety of macromolecules.

\section{Results}

\section{Environmental characterization of SYBH in March 2017}

In this $\sim 300 \mathrm{~m}$ deep blue hole, dissolved oxygen (DO) decreased from $6.34 \mathrm{mg} / \mathrm{L}$ at $0 \mathrm{~m}$ to zero at $100 \mathrm{~m}$, indicating that the environment above $100 \mathrm{~m}$ was oxic and below was anoxic; the concentration of DO dropped sharply (from 4.28 to $0.05 \mathrm{mg} / \mathrm{L}$ ) between 80 and $100 \mathrm{~m}$, indicating a DO-transition/suboxic zone. In addition, most physical and chemical parameters remained relatively uniform below the depth of $160 \mathrm{~m}$ (Yao et al. 2018). The water column could thus be divided into three zones; an oxic-suboxic zone (including the oxic zone and the suboxic zone, i.e., 0-90 m), a middle anoxic zone (100-160 m) and a bottom anoxic zone (160-230 m).

Water temperature decreased from $27.05{ }^{\circ} \mathrm{C}$ at the surface to $15.27^{\circ} \mathrm{C}$, salinity increased from 33.4 to $34.6 \mathrm{PSU}$, while $\mathrm{pH}$ ranged from 7.26 to 8.14 (Table $\mathrm{S} 1$ ) (Yao et al. 2018). Generally, $\mathrm{pH}, \mathrm{DO}$ and $\mathrm{NO}_{2}{ }^{-}$decreased with depth, whereas salinity, $\mathrm{NH}_{4}{ }^{+}, \mathrm{PO}_{4}{ }^{3-}$ and $\mathrm{SiO}_{3}{ }^{2-}$ showed opposite trends (Yao et al. 2018). DO was considered to be the main cause for these changes, while the other parameters, such as $\mathrm{NH}_{4}{ }^{+}, \mathrm{NO}_{3}{ }^{-}$and $\mathrm{PO}_{4}{ }^{3-}$, co-varied with DO (Yao et al. 2018). Therefore, there are significant connections between DO and other environmental factors. 


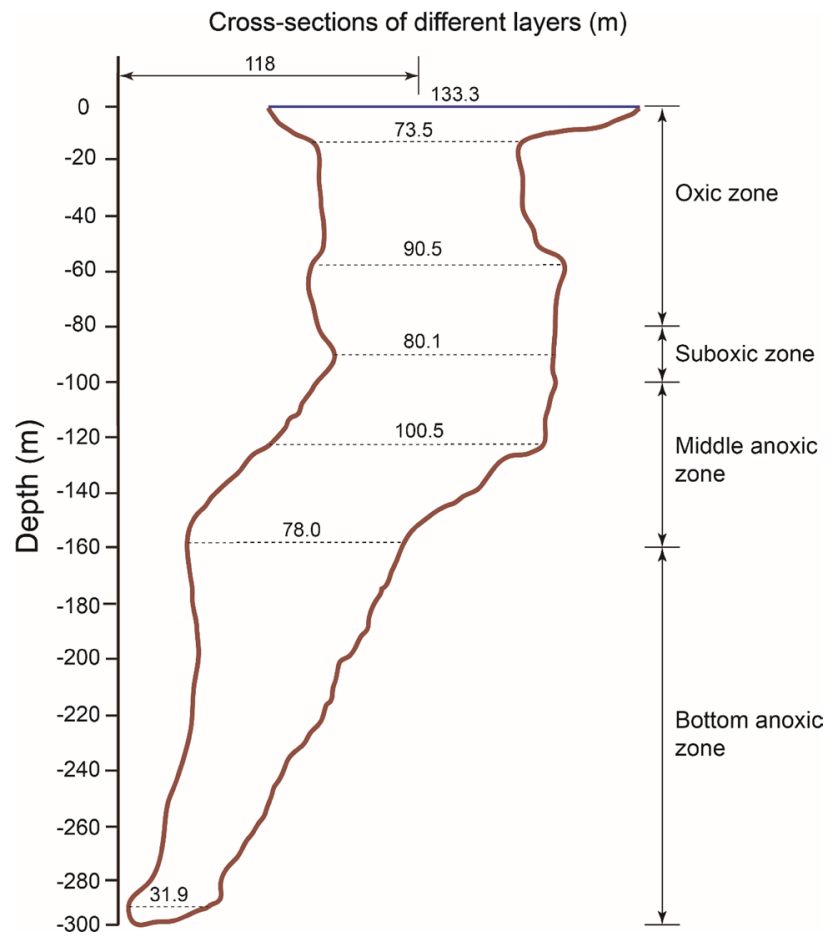

Fig. 1 Vertical section of SYBH at an azimuth of $30^{\circ}$ (modified from Xie et al. 2019)

\section{Abundance of Vibrio population in March 2017}

Because Vibrio spp. exhibit two alternative growth strategies, microorganisms were serially collected by $3-\mu \mathrm{m}$-pore size and $0.2-\mu \mathrm{m}$-pore size polycarbonate membranes, which were designated_F (free-living Vibrio) and _P (particleassociated Vibrio), respectively in the following analyses (Fig. 1).

The Vibrio population size ranged from $3.78 \times 10^{4}$ to $7.35 \times 10^{6} 16 \mathrm{~S}$ rRNA gene copies $\cdot \mathrm{L}^{-1}$ in the blue hole seawater (Table 1). The highest abundance was measured at $100 \_\mathrm{F}\left(7.35 \times 10^{6}\right.$ gene copies $\left.\cdot \mathrm{L}^{-1}\right)$ while the lowest was recorded at $170 \_\mathrm{P}\left(3.78 \times 10^{4}\right.$ gene copies $\left.\cdot \mathrm{L}^{-1}\right)$. The abundance of free-living Vibrio population ranged from $1.21 \times 10^{5}$ to $7.35 \times 10^{6}$ gene copies $\cdot \mathrm{L}^{-1}$, while the particle-associated Vibrio population varied from $3.78 \times 10^{4}$ to $9.08 \times 10^{5}$ gene copies $\cdot \mathrm{L}^{-1}$. The abundance of free-living Vibrio population $\left(\sim 1.20 \times 10^{6}\right.$ gene copies $\left.\cdot \mathrm{L}^{-1}\right)$ was significantly higher than that of particle-associated Vibrio population $\left(\sim 2.68 \times 10^{5}\right.$ gene copies $\left.\cdot \mathrm{L}^{-1}\right)(P<0.05)$ (Fig. 2$)$. It was found that the abundance of free-living Vibrio population in the samples had a positive correlation to salinity, $\mathrm{PO}_{4}{ }^{3-}$ and $\mathrm{SiO}_{3}{ }^{2-}$, and a negative correlation to $\mathrm{DO}$ and $\mathrm{pH}$. No parameters showed significant correlation with the abundance of particle-associated Vibrio population (Table 2).

The abundance of both the free-living and particle-associated Vibrio populations had no significant differences among

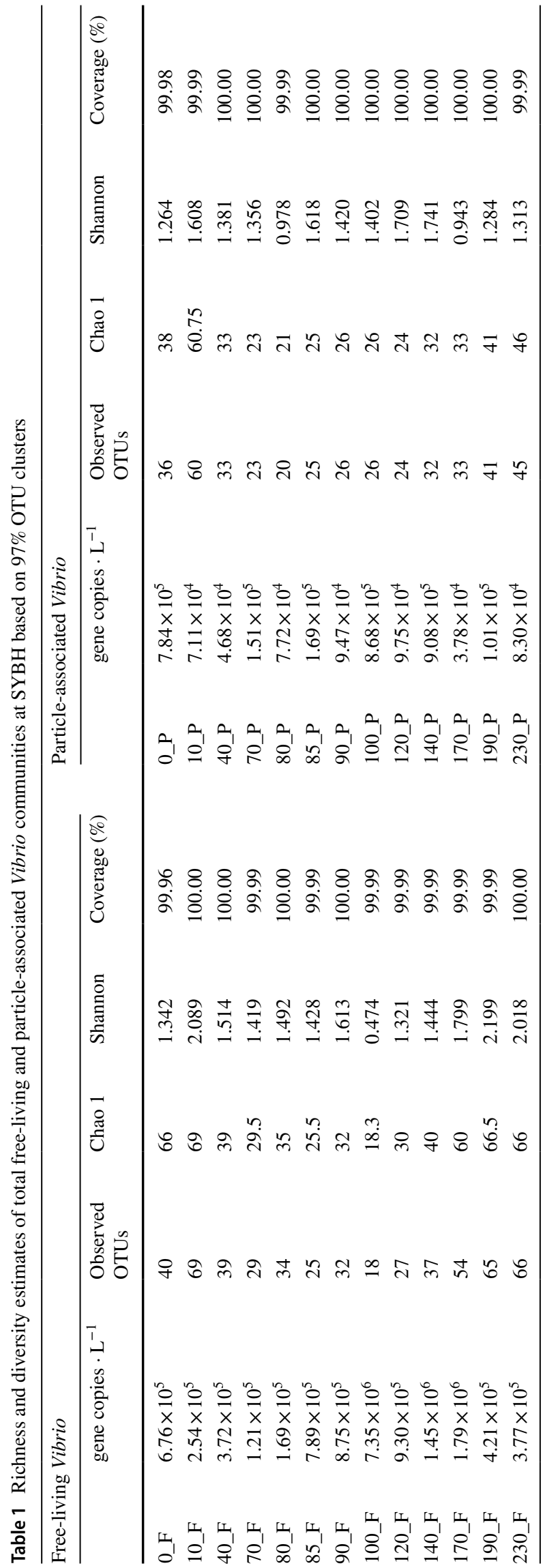




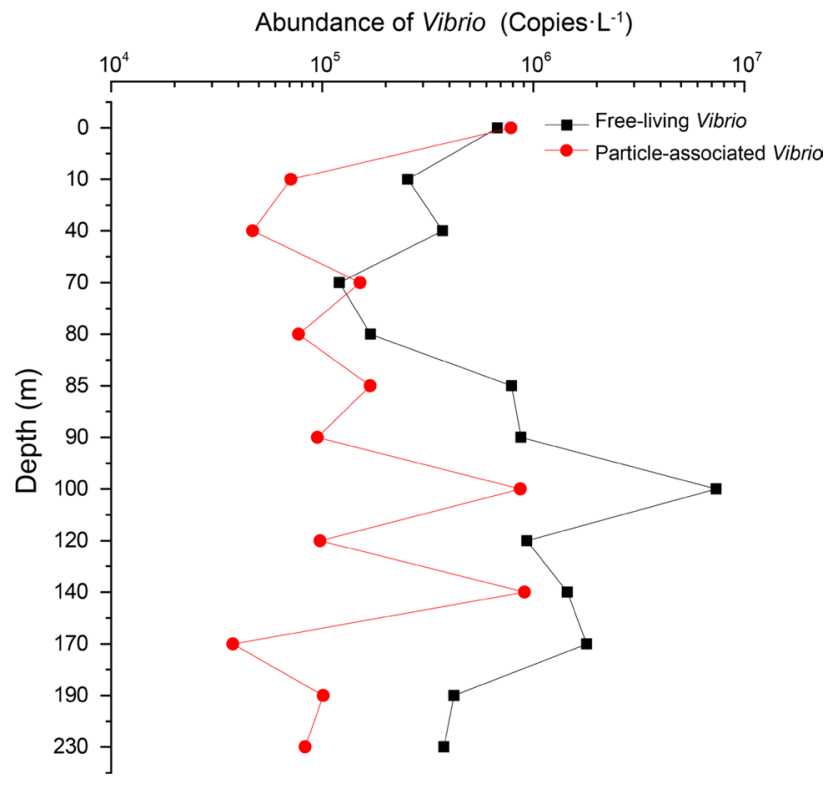

Fig. 2 The abundance of free-living and particle-associated Vibrio populations at different water depths of SYBH

the three depth-zones (Kruskal-Wallis test, $P>0.05$ ). Comparison of the relative proportions of Vibrio (i.e., proportion of Vibrio to total bacteria) in different sized fractions showed that Vibrio occur naturally and are an abundant group of marine microorganisms $(0.15 \%-15.94 \%$ of total bacteria) in SYBH (Fig. S1).

\section{Vibrio diversity and richness}

The samples studied here yielded high-quality sequences ranging from 25,645 to 43,959 reads, of which 25,094 sequences were left for each sample after normalizing. The average length of the obtained sequences was 512 base pairs. In total, 136 OTUs were clustered after randomly resampling, ranging from 18 to 69 OTUs per samples (Table 1), at a $97 \%$ similarity level. Good's coverages ranged from $99.96 \%$ to $100 \%$ in all the samples, indicating that most of the species in the study areas could be represented by the libraries generated by high-throughput sequencing.

Both the observed OTUs and Chao 1 index of free-living Vibrio were significantly higher than those of particle-associated Vibrio $(P<0.05$, Wilcoxon's rank test $)$, but there were no significant differences in the Shannon index between them. Moreover, the observed OTUs were highest in the oxic-suboxic zone (102 OTUs), while the middle anoxic zone and bottom anoxic zone contained 49 and 97 OTUs, respectively. The Chao 1 index was significantly higher in the bottom anoxic zone than in the middle anoxic zone $(P<0.05)$. In addition, there were no significant differences in diversity measures (including observed OTUs, Chao 1 index and Shannon index) between the oxic-suboxic zone and the middle anoxic zone $(P>0.05)$. The correlation coefficients between diversity indices and environmental factors are shown in Table 2; the observed OTUs and Chao 1 index of free-living and particle-associated Vibrio communities had consistently negative relationships with $\mathrm{NO}_{3}{ }^{-}$and $\mathrm{NO}_{2}{ }^{-}$.

\section{Vibrio community structure}

The taxonomy of each OTU was assigned against the Ezbiocloud database, with the 30 most abundant OTUs being shown in Fig. 3. Among the Vibrio OTUs (representing $>0.05 \%$ of the total normalized sequences), almost all sequences (98.89\%) belonged to the Vibrionaceae family

Table 2 Correlation coefficients between abundance/diversity indices of Vibrio population and environmental factors at SYBH

\begin{tabular}{|c|c|c|c|c|c|c|c|c|}
\hline \multirow[t]{2}{*}{ Environmental factors } & \multicolumn{4}{|c|}{ Free-living Vibrio } & \multicolumn{4}{|c|}{ Particle-associated Vibrio } \\
\hline & Abundance & Observed OTUs & Chao 1 & Shannon & Abundance & Observed OTUs & Chao 1 & Shannon \\
\hline Depth & 0.473 & 0.099 & 0.072 & 0.291 & 0.027 & 0.124 & 0.124 & -0.022 \\
\hline Temperature & -0.473 & -0.099 & -0.072 & -0.291 & -0.027 & -0.124 & -0.124 & 0.022 \\
\hline Salinity & $0.615^{*}$ & -0.045 & -0.028 & 0.109 & 0.168 & -0.006 & -0.006 & 0.173 \\
\hline $\mathrm{pH}$ & $-0.559 *$ & -0.198 & -0.193 & -0.391 & 0.066 & -0.247 & -0.247 & -0.008 \\
\hline DO & $-0.577^{*}$ & -0.057 & -0.068 & -0.226 & -0.051 & -0.091 & -0.091 & -0.147 \\
\hline $\mathrm{NO}_{3}^{-}$ & -0.066 & $-0.554^{*}$ & $-0.646^{*}$ & -0.264 & -0.121 & $-0.605^{*}$ & $-0.605^{*}$ & -0.129 \\
\hline $\mathrm{NO}_{2}^{-}$ & -0.301 & $-0.657^{*}$ & $-0.689 * *$ & -0.546 & 0.218 & $-0.607 *$ & $-0.607 *$ & 0.199 \\
\hline $\mathrm{NH}_{4}^{+}$ & 0.429 & 0.448 & 0.477 & 0.256 & -0.036 & 0.503 & 0.503 & -0.234 \\
\hline $\mathrm{PO}_{4}^{3-}$ & $0.571^{*}$ & 0.055 & 0.041 & 0.231 & 0.027 & 0.069 & 0.069 & -0.104 \\
\hline $\mathrm{SiO}_{3}{ }^{2-}$ & $0.571^{*}$ & 0.055 & 0.041 & 0.231 & 0.027 & 0.069 & 0.069 & -0.104 \\
\hline
\end{tabular}

Correlation coefficient is a positive value, indicating a positive correlation; correlation coefficient is a negative value, indicating a negative correlation

*Significantly related

**Extremely significant related 


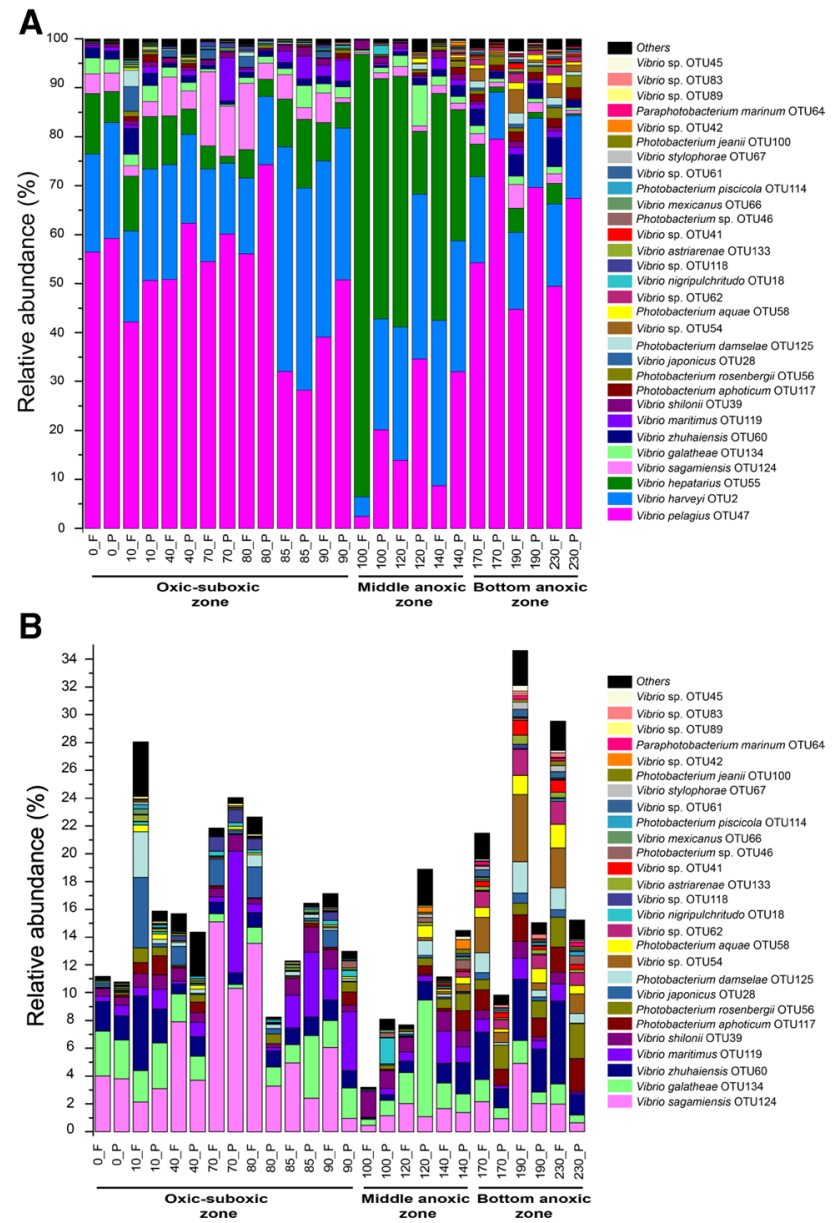

Fig. 3 Vibrio community compositions at OTU level across all samples. _F and _P stand for free-living Vibrio and particle-associated Vibrio, respectively: (a) the most abundant 30 OTUs; (b) the most abundant 30 OTUs except the dominant 3 OTUs

and $96.34 \%$ were assigned to the genus Vibrio. Seven OTUs (composed of all OTUs with $>1.0 \%$ of relative abundance in the total sequences) representing the most abundant species in the population, comprised $93.01 \%$ of the sequences among all samples. These seven OTUs included OTU47 (most similar to V. pelagius; accounting for $45.93 \%$ ), OTU2 (most similar to $V$. harveyi; $22.40 \%$ ), OTU55 (most similar to $V$. hepatarius $15.49 \%$ ), OTU124 (most similar to V. sagamiensis; 3.91\%), OTU134 (most similar to V. galatheae; $1.96 \%$ ), OTU60 (1.88\%; most similar to V. zhuhaiensis) and OTU119 (most similar to V. maritimus; $1.45 \%$ ).

The dominant groups differed significantly between each zone (Fig. 3); V. pelagius OTU47, V. harveyi OTU2, V. hepatarius OTU55 and V. sagamiensis OTU124 dominated the oxic-suboxic zone, $V$. hepatarius OTU55 and $V$. harveyi OTU2 dominated the middle anoxic zone, whereas $V$. pelagius OTU47 and $V$. harveyi OTU2 were the dominant groups in the bottom anoxic zone. To investigate the differences in free-living and particle-associated Vibrio, the absolute abundance of dominant OTUs was calculated by multiplication of the total abundance of Vibrio and their relative proportions in the Vibrio communities (Table S3). It was found that the abundance of the dominant groups in the free-living fraction was greater than in the particle-associated fraction. No significant differences were observed among the three depth zones for $V$. pelagius OTU47 and $V$. harveyi OTU2, but the abundance of $V$. hepatarius OTU55 was higher in the middle anoxic zone than in the other two depth zones.

While there were no marked differences in the Vibrio community compositions between free-living and particleassociated fractions, significant vertical shifts were observed among the three depth-zones (Fig. 4a). The first two principal components explained $49.89 \%$ of the total community variation. Clear variations between the depths below $170 \mathrm{~m}$ and other depths were found along the first axis, whereas $0-90 \mathrm{~m}$ and $100-140 \mathrm{~m}$ could be separated by the second axis.

The relationship between Vibrio community compositions and environmental factors at the OTU level was analyzed by db-RDA (Fig. 4b); RDA1 and RDA2 together explained $43.88 \%$ of the total variance among the samples. Two size fractions (_F and _P) at each depth were similar (Fig. 4b), so environmental factors shaped the same distribution of free-living and particle-associated Vibrio community at the same depth. Monte Carlo permutation tests showed that $\mathrm{NH}_{4}{ }^{+}(F=9.3, P=0.002), \mathrm{PO}_{4}{ }^{3-}(F=8.8, P=0.002)$, $\mathrm{SiO}_{3}{ }^{2-}(F=7.2, P=0.002)$, temperature $(F=6.4, P=0.002)$, pH $(F=6.4, P=0.002)$, DO $(F=3.9, P=0.002)$, salinity $(F=4.3, P=0.004)$, and $\mathrm{NO}_{2}{ }^{-}(F=2.2, P=0.03)$ significantly contributed to the Vibrio community structure.

Spearman's correlations between the relative abundance of the 30 most abundant OTUs and environmental factors were calculated. For both the free-living (Table S4) and particle-associated (Table S5) Vibrio communities, the three most dominant OTUs (V. pelagius OTU47, V. harveyi OTU2, and $V$. hepatarius OTU55) had no correlations with the tested environmental factors; many OTUs, which included most OTUs comprising $<4.0 \%$ of total sequences, demonstrated correlations with some of the environmental factors. For free-living Vibrio communities, the relative abundance of $V$. sagamiensis OTU124 was positively related to $\mathrm{DO}$ and $\mathrm{NO}_{3}{ }^{-}$, and negatively related to $\mathrm{NH}_{4}{ }^{+} ; V$. zhuhaiensis OTU60 and V. maritimus OTU119 were negatively correlated with $\mathrm{NO}_{2}{ }^{-}$and DO, respectively. For particleassociated Vibrio communities, V. sagamiensis OTU124 was negatively correlated to depth, $\mathrm{PO}_{4}{ }^{3-}, \mathrm{SiO}_{3}{ }^{2-}$ and salinity $(P<0.01)$, and positive correlated to temperature, DO, $\mathrm{pH}$, and $\mathrm{NO}_{2}{ }^{-}(P<0.01)$. In addition, the relative abundance of $V$. zhuhaiensis OTU60 and $V$. maritimus OTU119 were negatively correlated with $\mathrm{NO}_{3}{ }^{-}$and $\mathrm{NO}_{2}{ }^{-}$, and $\mathrm{NH}_{4}{ }^{+}$and DO, respectively. Within the top 30 OTUs, Vibrio sp. OTU61 and Vibrio sp. OTU45 occurred only in the anoxic water 
A

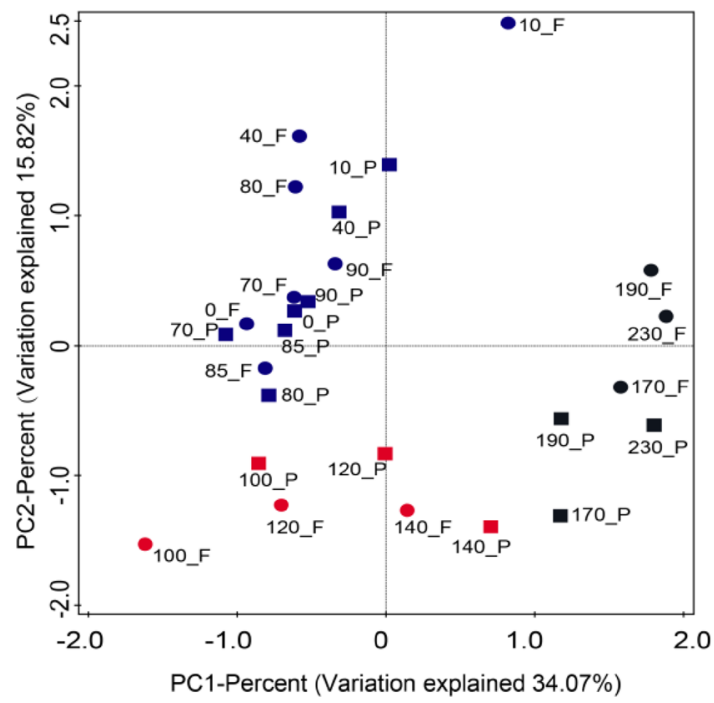

Fig. 4 Community analysis of Vibrio and the relationship with environmental factors: (a) UniFrac principal coordinate analysis (PCoA) of different samples based on OTUs assigned at $97 \%$ sequence similarity; (b) db-RDA diagram illustrating the relationship between Vibrio community and environmental variables based

below $140 \mathrm{~m}$, and Vibrio sp. OTU83 was present solely below $170 \mathrm{~m}$.

\section{Cultivable Vibrio spp. and their abilities to digest various macromolecules}

To understand the ability of Vibrio spp. to degrade various macromolecules, an attempt was made to isolate Vibrio cultures from seawater at different depths of SYBH. From the two cruises, 19 species of Vibrionaceae (in total 178 isolates) were cultured, including $V$. antiquaries (79 isolates), V. neocaledonicus (19 isolates), V. parahaemolyticus (17 isolates), V. owensii (8 isolates), V. azureus (7 isolates), $V$. harveyi (6 isolates), V. tubiashii (5 isolates), V. alginolyticus (5 isolates), V. nigripulchritudo (4 isolates), V. japonicas (4 isolates), $V$. galatheae (2 isolates), $V$. maritimus (2 isolates), V. fluvialis (2 isolates), V. proteolyticus (1 isolate), $V$. hyugaensis (1 isolate), V. atypicus (1 isolate), Catenococcus thiocycli (10 isolates), Photobacterium damselae (1 isolate) and a potential new Vibrio species (4 isolates, isolated from the anaerobic microorganisms incubation media). All Vibrionaceae isolates (except the four potential new Vibrio isolates) and the depths isolated are shown in Fig. S2; the $16 \mathrm{~S}$ rRNA genes of 91 isolates were sequenced and their GenBank accession numbers are shown in Table S6.

Media supplemented with a variety of macromolecules were used to detect extracellular enzymes. Of the 178 Vibrionaceae isolates cultured, 46 isolates consisting of 15 Vibrio species, were selected to test their extracellular
B

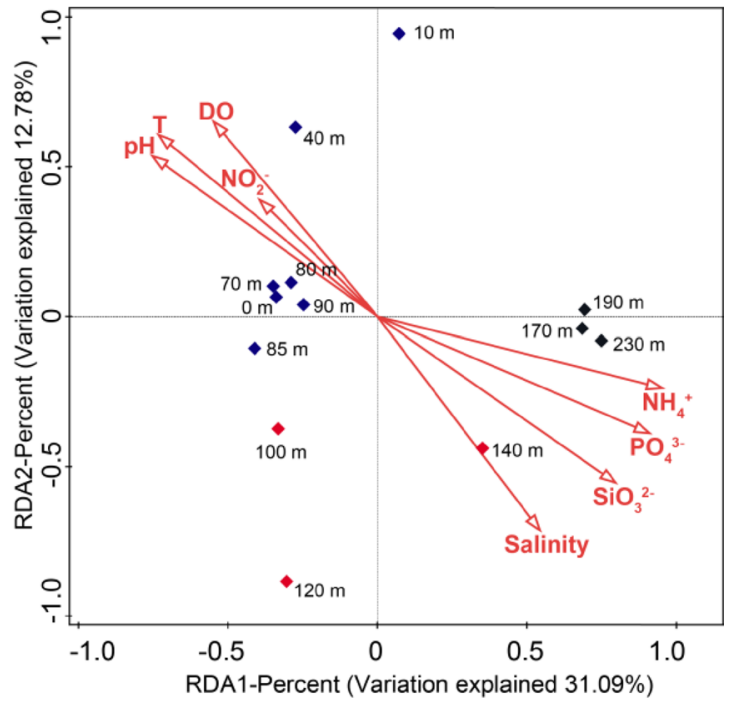

on OTUs assigned at $97 \%$ sequence similarity. Blue, oxic-suboxic zone (0-90 m); red, middle anoxic zone (100-140 m); black, bottom anoxic zone (170-230 m). Dot, free-living Vibrio; square, particleassociated Vibrio; rhombus, free-living Vibrio and particle-associated had the same distribution in the db-RDA

enzymes, and 45 isolates were found to display at least one hydrolytic enzymatic activity. The ratio of hydrolysis circle diameter and colony diameter in the media indicated activity strength (Table S7). A total of 15 types of extracellular enzymatic activities detected at $28{ }^{\circ} \mathrm{C}$ were summarized in Fig. 5. Amylase, gelatinase, Tween 40 lipase and $\kappa$-carrageenanase producing strains ( 45 out of 46 isolates) were prevalent. Caseinase and lecithinase positive strains comprised a considerable proportion (39 and 38 out of 46 isolates, respectively), while none of the isolates displayed cellulolytic activity. The numbers of isolates that could degrade DNA, Tween 20 and Tween 80 at $28{ }^{\circ} \mathrm{C}$ were 35 , 33 and 18 , respectively. The numbers of isolates that were

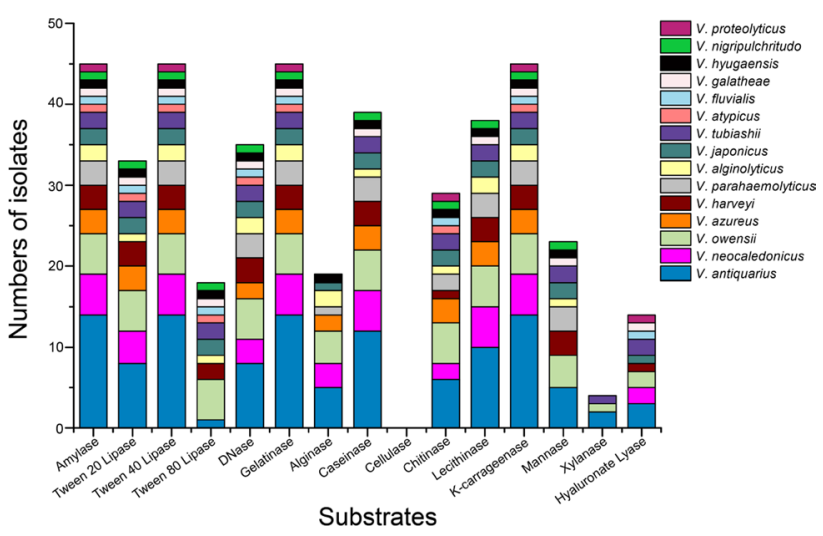

Fig. 5 Hydrolytic enzyme activities at $28{ }^{\circ} \mathrm{C}$ among all 46 isolates from the water collected in SYBH 
able to degrade chitin and alginate were 29 and 19, respectively. A $V$. owensii isolate cultured from the seawater at the depth of $170 \mathrm{~m}$ had no tested extracellular enzymes activities. Generally, Vibrio responded rapidly to all these macromolecules. For organic carbon sources readily available (including starch, Tween 20/40/80, gelatin, casein, DNA, lecithin, $\kappa$-carrageenan and hyaluronic acid), the transparent zones or hydrolytic circles could be observed after 1 day of culture. However, typically 1-2 weeks were required for other bacteria to utilize chitin (Zhang et al. 2016), while the transparent zones could be observed after 3 days' incubation.

\section{Discussion}

Vibrio is a ubiquitous group of metabolically flexible marine heterotrophic bacteria, that play an important role in biogeochemical cycling in the ocean. There have been many studies on the diversity and dynamics of Vibrio populations in a variety of marine environments, including the MidAtlantic, Mediterranean coast, Australian coast, Japan surrounding seawater, and Chinese marginal seas (Amin et al. 2016; Girard et al. 2017; Liang et al. 2019; Mansergh and Zehr 2014; Siboni et al. 2016; Wang et al. 2019; Westrich et al. 2018). The distribution of Vibrio population in marine environment is influenced by many environmental factors including salinity, temperature, and in some cases the abundance of host organisms (Thompson et al. 2004b). However, little is known about Vibrio diversity and abundance in the unique environment of blue holes. To the best of our knowledge, this is the first investigation of a Vibrio community in a blue hole.

Environmental parameters (such as water chemistry) may strongly affect the spatial and taxonomic distributions of indigenous microbial communities and the trophic levels of food webs in blue holes (Gonzalez et al. 2011; Hoffman et al. 2018; Seymour et al. 2007). However, previous studies have either provided microbial profiles at a broad taxonomic level or have focused mainly on the water samples collected from specific depths within the cave (Gonzalez et al. 2011; Hoffman et al. 2018). A more resolved study targeting a finer taxonomic level can enhance our understanding of accurate microbial distribution patterns in response to environmental changes (Liu et al. 2015). Here, as a complement to previous studies, the vertical distribution patterns of Vibrio communities as well as the abilities to digest various macromolecules by the cultivable Vibrio was investigated.

\section{Characteristics of Vibrio communities within the SYBH}

In this study, Vibrio-specific 16S rRNA gene primers were used to sequence Vibrio communities in seawater samples from different depths of SYBH, South China Sea. The variation of Vibrio community structure was mainly caused by the pronounced vertical layering, and the whole community could be divided into three groups: an oxic-suboxic zone $(0-90 \mathrm{~m})$, a middle anoxic zone $(100-140 \mathrm{~m})$ and a bottom anoxic zone $(170-230 \mathrm{~m})$. A similar structure was found in the Cariaco Basin, which is the second largest permanently anoxic marine water in the world (Garcia-Amado et al. 2011). There also, Vibrio could be divided into three groups: an oxic zone (0-200 m), a redox zone (230-280 m) and an anoxic zone (400-1300 m), according to the OTU composition and the water depth. The vertical change in SYBH occurred at two distinct depths; from oxic to anoxic (90-100 m) and within the anoxic water from depths where environmental parameters stopped changing (140-170 m).

The abundance of Vibrio was high at $100 \mathrm{~m}$ depth (Fig. 2). At this depth (the interface of oxic-anoxic) both aerobic and anaerobic Vibrio spp., with two kinds of metabolism modes (i.e., respiration and fermentation modes) existed. However, higher nutrient levels occurred at the interface of oxic-anoxic zone (Yao et al. 2018), which may have caused the increase in Vibrio abundance. The high abundance at this depth indicates that there might be organic substances preferred by Vibrio here. However, little is known about the composition of the organic matters in SYBH, and it is worth further investigation.

The sequencing analysis of the 16S rRNA gene showed that $V$. hepatarius was the dominant species at depths between 100 and $140 \mathrm{~m}$ but was most abundant at $100 \mathrm{~m}$. $V$. hepatarius was originally isolated from the hepatopancreas of shrimp (Thompson et al. 2003) and since then has been found in the haemolymph of the spider crab (Gomez-Gil et al. 2010), the digestive tract of Holothuria scabra (Plotieau et al. 2013) and diseased tissue of coral reefs (Séré et al. 2013), suggesting that $V$. hepatarius may prefer utilizing specific substrates derived from animal hosts. In addition, the micro-oxic environment of these animal tissues is in line with the facultative anaerobic metabolic mode of $V$. hepatarius as previously reported (Thompson et al. 2003). This may indicate that animal-derived organic matter accumulates in the transition oxic-anoxic zone; however, this requires further confirmation.

The abundance of free-living Vibrio population was significantly higher than that of particle-associated Vibrio population, suggesting that Vibrio spp. prefer a free-living style. Similar results have also been observed in other marine environments, including the Baltic and Skagerrak Seas and the northern Chinese marginal seas (Eiler et al. 2006; Liang et al. 2019). It was reported that the number of particle-associated bacteria was low in the open ocean, primarily due to the low concentration of particulate material (Unanue et al. 1992). Similarly, free-living Vibrio populations are more abundant than particle-associated ones, most 
likely because of the low particle concentrations in SYBH. Unfortunately, CFUs values on TCBS were not counted, so qPCR and CFU values could not be compared.

The Vibrio community in this special habitat of SYBH in terms of diversity and species richness is significantly different from other marine environments, such as estuaries, offshore and open sea ecosystems. To withstand the variable and complex conditions, it was necessary for Vibrio to develop a high species diversity (Liang et al. 2019). At SYBH, Vibrio-specific 16S rRNA gene-based sequencing retrieved a total of 136 OTUs, while a similar study at 21 sites of the northern Chinese marginal seas retrieved only 74 OTUs (Liang et al. 2019).

One potentially novel Vibrio species (Vibrio sp. JC009) from $130 \mathrm{~m}$ was cultured by the anaerobic cultivation technique and the full 16S rRNA gene sequence (1515 bp) showed the highest similarity to Vibrio olivae IGJ1.11 $(95.60 \%)$. Interestingly, strain JC009 was strictly anaerobic and could not grow in the presence of oxygen, whereas all known Vibrio species are facultative anaerobic (Farmer et al. 2015). Thus, it is possible that the strictly anaerobic property of this new strain might have resulted from long term adaption to the permanently anoxic environment of the SYBH.

\section{Controls on Vibrio abundance and community composition in the SYBH}

The results of qPCR assays indicated that Vibrio populations were present in all samples, suggesting that Vibrio was an abundant and natural component in SYBH. The abundance of Vibrio has been demonstrated to be largely related to temperature and salinity (Caburlotto et al. 2012; Siboni et al. 2016; Takemura et al. 2014). Salinity was likewise found to be significantly influential on the abundance of free-living Vibrio population of this study. Indeed, several Vibrio species with a higher salinity preference (high-salinity populations, such as V. pelagius) were found in the blue hole (Eiler et al. 2006) and some species (such as Vibrio sp. OTU54) were positively correlated with salinity, suggesting that they have evolved to adapt to the high salinity. However, no clear correlations between the abundance of Vibrio and temperature in SYBH was observed (Table 2), possibly due to the strong DO gradient. Similarly, it was found that cyanobacterial-derived organic matter played a more important role than temperature in a previous study (Eiler et al. 2007).

DO is an important hydrological parameter that affects the abundance of Vibrio population by affecting their metabolic processes. Due to oxygen depletion, Vibrio populations would switch from respiration to fermentation mode (Garcia-Amado et al. 2011). The strong stratification in SYBH limits the vertical exchange of oxygen, resulting in two distinct water bodies, an upper oxic region and a bottom anoxic region (Bi et al. 2018). Turner et al. (2009) found that
Vibrio abundance in both free-living and particle-associated fractions were inversely correlated with DO (48.7\%-105.8\% saturation) along the coast of Georgia, USA. A negative correlation between the abundance of Vibrio and DO ( 5 to $11 \mathrm{mg} \mathrm{L}^{-1}$ ) has been found in North Carolina estuaries (Blackwell and Oliver 2008). Similar results were obtained in the present study. It should be noted that all the previous studies that investigated the correlation between Vibrio abundance and DO focused on oxic seawater; this study is the first to explore the correlation between Vibrio abundance and DO in an oxic-anoxic gradient seawater.

DO (together with its co-varied parameters, such as $\mathrm{NH}_{4}{ }^{+}, \mathrm{NO}_{3}{ }^{-}$and $\mathrm{PO}_{4}{ }^{3-}$ ), temperature and salinity were found to control the vertical structuring of the Vibrio community, although Vibrio abundance and temperature were not significantly correlated. Generally, the persistence of Vibrio communities depends on many factors, but the most important factors are salinity and temperature (Matteucci et al. 2015; Siboni et al. 2016). Since many Vibrio species can tolerate a wide range of temperature and salinity, these two factors may not lead to significant Vibrio species changes. In fact, DO has been reported as one of the major environmental parameters shaping Vibrio community composition in the Cariaco Basin (Garcia-Amado et al. 2011). In this study, the concentration of DO varied greatly from the surface to the bottom and this may have caused the significant metabolic alternation and thus species variations. Many heterotrophic bacteria are capable of anaerobic growth with nitrogen oxides (such as $\mathrm{NO}_{3}^{-}$) as electron acceptors instead of oxygen, while Vibrio spp. demonstrated the most efficient anoxic growth (Lacko et al. 2003). In anoxic water, the availability of an electron acceptor may be a key factor determining the survival and growth of Vibrio species. Concomitantly, correlations between Vibrio species and nitrogen oxides were found, indicating that nitrogen oxides may act as electron acceptors for Vibrio species dwelling in the anoxic water. Although this hypothesis needs further verification, the discovery of a diverse Vibrio community in anoxic water is very interesting, since no Vibrio species have previously been found to live strictly anaerobically.

Chemical elements, such as $\mathrm{N}, \mathrm{P}$, and $\mathrm{Si}$, are essential components for the growth of marine organisms, and $\mathrm{PO}_{4}{ }^{3-}$ and $\mathrm{SiO}_{3}{ }^{2-}$ in particular were found to contribute to the observed variations in the Vibrio community (Jahid et al. 2006; Paranjpye et al. 2015; Takemura et al. 2014). This suggests that nitrogen oxides and $\mathrm{NH}_{4}{ }^{+}$may alternatively serve as important resources for Vibrio species, thus affecting their abundance and diversity (Machado and Bordalo 2014; Siboni et al. 2016). The db-RDA analyses undertaken here indeed identified $\mathrm{NH}_{4}{ }^{+}$as the most important factor with the greatest explanatory power. The importance of $\mathrm{NH}_{4}{ }^{+}$ in explaining Vibrio distribution has also been observed in previous studies (Kopprio et al. 2017; Machado and Bordalo 
2014). Thus, nutrients (as well as organic matter) are important in shaping the Vibrio diversity and distribution (Kopprio et al. 2017). Considering that $\mathrm{NH}_{4}{ }^{+}, \mathrm{PO}_{4}{ }^{3-}$, etc. were co-varied with DO, DO may contribute mostly to the vertical structure of the Vibrio spp. community.

\section{The abilities of Vibrio isolates to digest various macromolecules}

In this study, 167 Vibrio strains (belong to 17 species) from two cruises at the SYBH were isolated using different culture media. Four Vibrio species, including $V$. harveyi, $V$. maritimus, V. japonicus and V. nigripulchritudo, were identified by both cultivation and high-throughput sequencing methods. One reason that only four species were identified by both methods was that it was impossible to isolate all the Vibrio species as all the cultivation methods were selective. Another reason was that the average length of the 16S rRNA sequences obtained from the high-throughput sequencing was only $\sim 500 \mathrm{bp}$, so many OTUs could not be assigned to a specific species. In addition, as primer mismatches may exist in the 16S rRNA gene high-throughput sequencing, not all the Vibrio species could be generated from the amplicons.

Vibrio species are suggested to play important roles in marine biogeochemical cycles, especially the organic carbon cycle (Simidu and Tsukamoto 1980; Zhang et al. 2018). Vibrio plays a role in nutrient cycling in aquatic environments by uptaking dissolved organic matter, or degrading many types of organic carbon by producing extracellular enzymes (Thompson et al. 2004a). Small molecules produced by macromolecular hydrolysis may be utilized by other marine bacteria, which may provide the basis for the formation of nutrient chains in microbial communities.

The Vibrio species isolated from SYBH in this study were able to produce a variety of highly active extracellular enzymes with generally larger hydrolytic circles, capable of breaking down 14 out of 15 macroorganic substrates tested. The reasons for having highly diverse extracellular enzymes in Vibrio might be as following. Firstly, there might be a range of substrates in SYBH, leading Vibrio isolates to produce a diverse range of extracellular enzymes here. Secondly, the genomes of Vibrio spp. are highly plastic, enabling them to have a broad metabolic range and produce a range of extracellular enzymes (Zhang et al. 2018). Vibrio isolates were able to make use of high diverse commonly existing organic substrates, indicating that they might play an important role in driving organic carbon cycling in SYBH.

As the detection of carbon substrates in natural environments is still technically difficult, no attempt was made to detect the carbon substrates in SYBH. Fifteen commonly used substrates were selected to test the abilities of Vibrio in SYBH to degrade macromolecules. To make this study more environmentally relevant, the organic matter present in SYBH should also be examined in future studies. In addition, although the results from the degradation of macromolecules are preliminary, this screening may provide a resource to discover novel biocatalysts (Zhang et al. 2016). The enzymes produced from Vibrio may have a great potential for biotechnology, due to the fast growth rate with shorter generation-times of the organisms (Zhang et al. 2018). An isolate of $V$. fluvialis, which can produce an alkaline extracellular protease with high efficiency and good stability, was considered to be in industrial detergents (Venugopal and Saramma 2006).

\section{Conclusions}

In summary, abundant, unique and highly diverse Vibrio communities were present in the SYBH. The vertical variations and diversity of the Vibrio community seemed to be influenced simultaneously by a range of environmental factors (such as DO, temperature, salinity and $\mathrm{pH}$ ) rather than an individual one and different Vibrio species responded to the environmental factors differently. The cultivated Vibrio isolates were able to degrade many different macro organic substrates efficiently, suggesting their potential important roles in the organic carbon cycle. In the future, a more extensive analysis of the effect of environmental parameters, such as organic carbon availability, on Vibrio community compositions may provide a better insight into how these factors affect Vibrio population dynamics. Since Vibrio populations might have significant influence over nutrient availability through utilizing chitin and other carbon substrates, understanding the role of the Vibrio populations in the SYBH may help to better constrain the carbon cycle in this unique environment.

\section{Materials and methods}

\section{Water sampling and environmental factors}

Water sampling at SYBH (Fig. 1) was conducted onboard the R/V Qiongqionghai 03138 during a spring and a summer cruise. During the two cruises, a Niskin bottle (5 L) was used to collect the water samples from depths between 0 and $190 \mathrm{~m}$; an underwater robot (VideoRay Pro4 ROV) with the same Niskin bottle was used to collect water deeper than $190 \mathrm{~m}$, due to the curved shape of the walls of the blue hole at depth. In the spring cruise (14-20 March, 2017), water samples from 13 depths $(0,10,40,70,80,85$, $90,100,120,140,170,190$ and $230 \mathrm{~m}$ ) were collected. One liter water sample from each depth was pre-filtered through 
3- $\mu \mathrm{m}$-pore size polycarbonate membranes (Millipore Corporation, Billerica, MA, USA) to collect particle-associated microorganisms. The free-living microorganisms were then collected through $0.2-\mu \mathrm{m}$-pore size polycarbonate membranes (Millipore). The filters were frozen at $-80{ }^{\circ} \mathrm{C}$ until DNA extraction. The water samples were immediately inoculated into anoxic liquid media contained in acidwashed, sterile $\left(121{ }^{\circ} \mathrm{C} / 20 \mathrm{~min}\right) 200 \mathrm{~mL}$ glass bottles for enrichment of the anaerobic microorganisms; additional water samples were stored in sterile closed bottles (acidwashed, $100 \mathrm{~mL}$ ) at $4{ }^{\circ} \mathrm{C}$, and inoculated for other types of bacterial cultivation within $1 \mathrm{~h}$ of sampling. In the summer cruise (14-15 June, 2017), water samples were collected from 27 depths $(15,20,30,50,60,75,95,105,110,130$, $150,160,180,270 \mathrm{~m}$, plus 13 depths as in March); these samples were only used for bacterial cultivation.

Environmental parameters of water samples were detected by either CTDs or AA3 Auto-Analyzer. Briefly, water chemistry such as salinity, temperature, $\mathrm{pH}$ and $\mathrm{DO}$ were monitored with Alec ASTD102 CTD (JFE Advantech Co., Japan) at 0-190 m, and YSI EXO CTD (YSI Co., USA) at depths greater than $190 \mathrm{~m}$, respectively. Samples for nutrients, including nitrite $\left(\mathrm{NO}_{2}{ }^{-}\right)$, nitrate $\left(\mathrm{NO}_{3}{ }^{-}\right)$, ammonium $\left(\mathrm{NH}_{4}{ }^{+}\right)$, silicate $\left(\mathrm{SiO}_{3}{ }^{2-}\right)$ and phosphate $\left(\mathrm{PO}_{4}{ }^{3-}\right)$, were filtered with $0.45-\mu \mathrm{m}$ cellulose acetate membranes and analyzed with spectrophotometric and colorimetric methods, using an AA3 Auto-Analyzer (Seal Analytical, UK) (Yao et al. 2018).

\section{Bacterial isolation}

For isolation of Vibrionaceae strains, $200 \mu \mathrm{L}$ of seawater sample was spread onto marine agar 2216E (Becton-Dickinson), marine R2A agar (Fluka R2A agar was prepared with seawater instead of distilled water) and Vibrio selective medium TCBS (thiosulfate-citrate-bile salt-sucrose) agar, and inoculated into media for anaerobic microorganisms (Wang et al. 2015) and sulfur-oxidizing bacteria (Du et al. 2019). The anaerobic bacteria were enriched for 1 month in liquid media under an atmosphere of mixed gas $\left(10 \% \mathrm{H}_{2}, 20 \% \mathrm{CO}_{2}\right.$ and $\left.70 \% \mathrm{~N}_{2}\right)$ at $16{ }^{\circ} \mathrm{C}$, then the bacterial suspension was spread on marine agar $2216 \mathrm{E}$ in an anaerobic packet of AneroPack-Anaero (Mitsubishi Gas Chemical Co., Japan) for bacterial purification ( $\mathrm{Fu}$ et al. 2018). The sulfur-oxidizing bacteria were enriched in liquid medium at $28{ }^{\circ} \mathrm{C}$ for 1 month in dark, and then the bacterial suspension was spread on solid medium (Du et al. 2019). The bacterial colonies were purified, preserved and sequenced to determine the phylogenetic characteristics according the method described by Yin et al. (2013).
DNA extraction and quantitative PCR (qPCR)

The filtered membranes were cut into small pieces and DNA on the filters were extracted by chemical (phenol-chloroform method) and mechanical lysis according to the method described by Yin et al. (2013), with additional steps to facilitate cell lysis by a Fast Prep-24 Homogenization System (MP Biomedicals, Irvine, CA, USA) and the addition of lysozyme and protease K. DNA quantity and purity was evaluated using a Nanodrop-1000 Spectrophotometer.

The abundance of the total Vibrio population was quantified by a SYBR Green qPCR method utilizing Vibrio-specific 16S rRNA gene primers V-567F (5'-GGCGTAAAG CGCATGCAGGT-3') (Thompson et al. 2004b) and V-680R (5'-GAAATTCTACCCCCCTCTACAG-3') (Thompson et al. 2004b). The reactions were performed in triplicate with negative controls at the following condition: an initial denaturation at $95^{\circ} \mathrm{C}$ for $5 \mathrm{~min}$, followed by 35 cycles of a 2-step reaction at $95{ }^{\circ} \mathrm{C}$ for $30 \mathrm{~s}$ and $64^{\circ} \mathrm{C}$ for $60 \mathrm{~s}$. The 20 $\mu \mathrm{L}$ qPCR experiments were run involved: $10 \mu \mathrm{L}$ SYBR Premix Ex Taq II $(2 \times), 0.4 \mu \mathrm{L}$ ROX Reference Dye II $(50 \times)$, $0.8 \mu \mathrm{L}$ forward and reverse primers $(10 \mu \mathrm{M}), 6 \mu \mathrm{L}$ sterile double-distilled water and $2 \mu \mathrm{L}$ DNA samples. To quantify the total bacteria, the 16S rRNA gene universal primer sets Eub338F/518R (Yin et al. 2013) were used. Each $20 \mu \mathrm{L}$ of quantitative PCR reaction solution contained the components described as Zheng et al. (2017), and the PCR protocol was at $95^{\circ} \mathrm{C}$ for $3 \mathrm{~min}$, followed by 35 cycles of $95^{\circ} \mathrm{C}$ for $30 \mathrm{~s}, 56^{\circ} \mathrm{C}$ for $30 \mathrm{~s}$, and $72{ }^{\circ} \mathrm{C}$ for $30 \mathrm{~s}$.

All qPCR assays performed on StepOne ${ }^{\mathrm{TM}}$ Real-time PCR System (Applied Biosystems) and StepOne software version 2.2, and standard curves (equivalent to $10^{1}-10^{7}$ gene copies $\mathrm{L}^{-1}$ ) for each qPCR assay were prepared according to Liang et al. (2019), obtained by amplifying pUCm-T (a plasmid, Sangon Co., China, and the inserted sequence of 16S rRNA gene was shown in Table S2). The efficiencies of the qPCR reactions varied from 95 to $105 \%$, with $R^{2}$ values $>99 \%$. In addition, a melting curve was added to the end of each qPCR assay, to confirm that each primer pair produced only a single specific product and agarose gels were generated if variance was observed among target sequences.

\section{PCR amplification and high-throughput sequencing}

The Vibrio-specific 16S rRNA gene primers V-169F (5'GGATAACC/TATTGGAAACGATG-3') (Liu et al. 2006) and V-680R (Thompson et al. 2004b) were used to detect Vibrio community compositions of the water samples at different depths. The PCR reactions and cycling conditions were performed as described by Liang et al. (2019). After confirming positive amplification, the PCR products from the samples were used to prepare DNA libraries with the Illumina TruSeq DNA library preparation protocol. 
Sequencing was performed on the Illumina MiSeq platform (Majorbio Bio-Pharm Technology Co., Ltd., Shanghai, China).

\section{Sequence processing and operational taxonomic unit (OTU) assignment}

The 16S rRNA gene data were analyzed on the online platform of Majorbio I-Sanger Cloud Platform (http://www.isanger.com). The SILVA database (SSU128) was used for taxonomic identification. The sequences were clustered into OTUs at the level of $97 \%$ and the classification confidence threshold was $70 \%$. The representative sequences of the top 30 OTUs were blasted against the EzBioCloud database (https://www.ezbiocloud.net), and the top-hit sequence was downloaded for each OTU, and OTUs with less than 97\% 16S rRNA gene similarities to known Vibrio species may be new species.

\section{Screening for the abilities of Vibrio isolates to digest various macromolecules}

For cultivated Vibrio isolates, the ability to digest macromolecules was detected by using different culture media with the method described by Zhang et al. (2016). The substrates included starch, Tween 20/40/80, DNA agar, gelatin, alginate, casein, chitin and lecithin. Mannan, $\kappa$-carrageenan, xylan and hyaluronic acid were used as substrates in marine agar 2216E plates to detect the additional extracellular enzymes. The appearance of transparent zones or hydrolytic circles in the media demonstrated the activities of a series of extracellular enzymes (Zhang et al. 2016).

\section{Statistical analysis}

The distribution and abundance matrix of OTUs was randomly resampled to equalize sampling efforts, and the observed OTUs, Chao 1 richness, Shannon diversity index and Good's coverage were calculated in I-sanger website. The normalized Shannon and Chao 1 index were used as proxies for diversity and richness and differences in the alpha diversity indices were tested using student's $t$ test. For the beta diversity, a principal coordinate analysis (PCoA) bi-plot was utilized to visualize relationships of Vibrio populations in the water samples. Distance-based-redundancy analyses (db-RDA) with 999 Monte Carlo permutation tests were conducted on Canoco (version 5) to evaluate the relationship between samples and environmental factors. Spearman's rank analysis was calculated with IBM SPSS statistics 22.0 software (SPSS Inc., Chicago, IL, USA) to define statistically significant relationships between environmental factors and diversity indices, and between environmental factors and Vibrio abundance.

\section{Availability of data}

The 16S rRNA gene high-throughput sequencing data were deposited into the National Center for Biotechnology Information (NCBI) Sequence Read Archive (SRA) database (accession number: PRJNA531757). The 16S rRNA gene sequencing data of 91 Vibrionaceae isolates were deposited at GenBank under the accession numbers MN028428 to MN028517 and MF942360.

Acknowledgments We appreciate all the scientists and crew members on the R/V Qiongqionghai 03138 during the expedition for their great efforts and help in sample collection. This work was supported by the National Natural Science Foundation of China (Grants nos. 41730530, 91751202 and 41476112).

Author contributions $\mathrm{XHZ}$ designed the experiments and analyzed the data. LF and ZY designed the cruise and provided the water samplers. $\mathrm{BL}$ analyzed the environmental sequencing data, and performed qPCR and the experiments for the abilities of Vibrio isolates to digest various macromolecules. JL analyzed the environmental sequencing data. SZ extracted the community DNA and isolated the strains from seawater. PY and LC analyzed the environmental factors. XHZ, BL, JL and XW wrote the manuscript. All authors edited and approved the final manuscript.

\section{Compliance with ethical standards}

Conflict of interest All the authors declare that there are no conflicts of interest.

Animal and human rights statement This article does not contain any studies with human participants or animals performed by any of the authors.

Open Access This article is distributed under the terms of the Creative Commons Attribution 4.0 International License (http://creativeco mmons.org/licenses/by/4.0/), which permits unrestricted use, distribution, and reproduction in any medium, provided you give appropriate credit to the original author(s) and the source, provide a link to the Creative Commons license, and indicate if changes were made.

\section{References}

Amin AK, Feng G, Al-Saari N, Meirelles PM, Yamazaki Y, Mino S, Thompson FL, Sawabe T, Sawabe T (2016) The first temporal and spatial assessment of Vibrio diversity of the surrounding seawater of coral reefs in Ishigaki, Japan. Front Microbiol 7:1185

Araki T, Higashimoto Y, Morishita T (1999a) Purification and characterization of $\kappa$-carrageenase from a marine bacterium, Vibrio sp. CA-1004. Fish Sci 65:937-942

Araki T, Tani S, Maeda K, Hashikawa S, Nakagawa H, Morishita T (1999b) Purification and characterization of $\beta$-1,3-xylanase from a marine bacterium, Vibrio sp. XY-214. Biosci Biotech Biochem 63:2017-2019

Bi N, Fu L, Chen H, Liu R, Chen L, Liu Q, Lin K, Yao P, Yang Z (2018) Hydrographic features of the Yongle blue hole in the South China Sea and their influential factors (in Chinese, abstract in English). Chin Sci Bull 63:2184-2186 
Blackwell KD, Oliver JD (2008) The ecology of Vibrio vulnificus, Vibrio cholerae, and Vibrio parahaemolyticus in North Carolina estuaries. J Microbiol 46:146-153

Bokranz M, Katz J, Schröder I, Roberton AM, Kröger A (1983) Energy metabolism and biosynthesis of Vibrio succinogenes growing with nitrate or nitrite as terminal electron acceptor. Arch Microbiol 135:36-41

Brankovits D, Pohlman JW, Niemann H, Leigh MB, Leewis MC, Becker KW, Iliffe TM, Alvarez F, Lehmann MF, Phillips B (2017) Methane- and dissolved organic carbon-fueled microbial loop supports a tropical subterranean estuary ecosystem. Nat Commun 8:1835

Caburlotto G, Bianchi F, Gennari M, Ghidini V, Socal G, Aubry FB, Bastianini M, Tafi M, Lleo MM (2012) Integrated evaluation of environmental parameters influencing Vibrio occurrence in the coastal Northern Adriatic Sea (Italy) Facing the Venetian Lagoon. Microb Ecol 63:20-31

Davis C (1992) Production of laminarinase and alginase by marine bacteria after starvation. FEMS Microbiol Lett 86:349-355

Du R, Yu M, Cheng J, Zhang J, Tian X, Zhang X-H (2019) Diversity and sulfur oxidation characteristics of cultivable sulfur oxidizing bacteria in hydrotherm fields of Okinawa Trough (in Chinese, abstract in English). Acta Microbiol Sin 59:1036-1049

Eiler A, Johansson M, Bertilsson S (2006) Environmental influences on Vibrio populations in northern temperate and boreal coastal waters (Baltic and Skagerrak Seas). Appl Environ Microbiol 72:6004-6011

Eiler A, Gonzalez-Rey C, Allen S, Bertilsson S (2007) Growth response of Vibrio cholerae and other Vibrio spp. to cyanobacterial dissolved organic matter and temperature in brackish water. FEMS Microb Ecol 60:411-418

Farmer Iii JJ, Michael Janda J, Brenner FW, Cameron DN, Birkhead KM (2015) Vibrio. In: Whitman WB, Rainey F, Kämpfer P, Trujillo M, Chun J, DeVos P et al (eds) Bergey's manual of systematics of archaea and bacteria. Wiley, New York, pp 1-79

Fu T, Jia C, Fu L, Zhou S, Yao P, Du R, Sun H, Yang Z, Shi X, Zhang $\mathrm{X}-\mathrm{H}$ (2018) Marinifilum breve sp. nov., a marine bacterium isolated from the Yongle Blue Hole in the South China Sea and emended description of the genus Marinifilum. Int J Syst Evol Microbiol 68:3540-3545

Furukawa S-i, Fujikawa T, Koga D, Ide A (1992) Purification and some properties of exo-type fucoidanases from Vibrio sp. N-5. Biosci Biotech Biochem 56:1829-1834

Garcia-Amado MA, Bozo-Hurtado L, Astor Y, Suarez P, Chistoserdov A (2011) Denaturing gradient gel electrophoresis analyses of the vertical distribution and diversity of Vibrio spp. populations in the Cariaco Basin. FEMS Microbiol Ecol 77:347-356

Garman KM, Garey JR (2005) The transition of a freshwater karst aquifer to an anoxic marine system. Estuaries 28:686-693

Gilbert JA, Steele JA, Caporaso JG, Steinbruck L, Reeder J, Temperton B, Huse S, McHardy AC, Knight R, Joint I, Somerfield P, Fuhrman JA, Field D (2012) Defining seasonal marine microbial community dynamics. ISME J 6:298-308

Girard L, Peuchet S, Servais P, Henry A, Charni-Ben-Tabassi N, Baudart J (2017) Spatiotemporal dynamics of total viable Vibrio spp. in a NW Mediterranean coastal area. Microbes Environ 32:210-218

Gomez-Gil B, Roque A, Lacuesta B, Rotllant G (2010) Diversity of vibrios in the haemolymph of the spider crab Maja brachydactyla. J Appl Microbiol 109:918-926

Gonzalez BC, Iliffe TM, Macalady JL, Schaperdoth I, Kakuk B (2011) Microbial hotspots in anchialine blue holes: initial discoveries from the Bahamas. Hydrobiologia 677:149-156

Hasan NA, Grim CJ, Lipp EK, Rivera IN, Chun J, Haley BJ, Taviani E, Choi SY, Hoq M, Munk AC, Brettin TS, Bruce D, Challacombe JF, Detter JC, Han CS, Eisen JA, Huq A, Colwell RR (2015) Deep-sea hydrothermal vent bacteria related to human pathogenic Vibrio species. Proc Natl Acad Sci USA 112:E2813-E2819

Hoffman SK, Seitz KW, Havird JC, Weese DA, Santos SR (2018) Diversity and the environmental drivers of spatial variation in
Bacteria and micro-Eukarya communities from the Hawaiian anchialine ecosystem. Hydrobiologia 806:265-282

Hsieh JL, Fries JS, Noble RT (2008) Dynamics and predictive modelling of Vibrio spp. in the Neuse River Estuary, North Carolina, USA. Environ Microbiol 10:57-64

Jahid IK, Silva AJ, Benitez JA (2006) Polyphosphate Stores Enhance the ability of Vibrio cholerae to overcome environmental stresses in a low-phosphate environment. Appl Environ Microbiol 72:7043-7049

Kopprio GA, Streitenberger ME, Okuno K, Baldini M, Biancalana F, Fricke A, Martinez A, Neogi SB, Koch BP, Yamasaki S, Lara RJ (2017) Biogeochemical and hydrological drivers of the dynamics of Vibrio species in two Patagonian estuaries. Sci Total Environ 579:646-656

Lacko N, Drysdale GD, Bux F (2003) Anoxic phosphorus removal by denitrifying heterotrophic bacteria. Water Sci Tech 47:17-22

Lee L-H, Raghunath P (2018) Vibrionaceae diversity, multidrug resistance and management. Front Microbiol 9:563

Letchumanan V, Chan KG, Lee LH (2015) An insight of traditional plasmid curing in Vibrio species. Front Microbiol 6:735

Letchumanan V, Chan KG, Pusparajah P, Saokaew S, Duangjai A, Goh BH, Ab Mutalib NS, Lee LH (2016) Insights into bacteriophage application in controlling Vibrio species. Front Microbiol 7:1114

Li L, Kato C, Horikoshi K (1999) Bacterial diversity in deep-sea sediments from different depths. Biodivers Conserv 8:659-677

Li T, Feng A, Liu Y, Li Z, Guo K, Jiang W, Du J, Tian Z, Xu W, Liu Y, Wang Y (2018) Three-dimensional (3D) morphology of Sansha Yongle Blue Hole in the South China Sea revealed by underwater remotely operated vehicle. Sci Rep UK 8:17122

Liang J, Liu J, Wang X, Lin H, Liu J, Zhou S, Sun H, Zhang X-H (2019) Spatiotemporal dynamics of free-living and particleassociated Vibrio communities in the northern Chinese marginal seas. Appl Environ Microbiol 85:e00217-e00219

Liu Y, Yang GP, Wang HL, Chen JX, Shi XM, Zou G, Wei QW, Sun XQ (2006) Design of Vibrio 16S rRNA gene specific primers and their application in the analysis of seawater Vibrio community. J Ocean Univ China 5:157-164

Liu J, Fu B, Yang H, Zhao M, He B, Zhang X-H (2015) Phylogenetic shifts of bacterioplankton community composition along the Pearl Estuary: the potential impact of hypoxia and nutrients. Front Microbiol 6:64

Liu J, Zheng Y, Lin H, Wang X, Li M, Liu Y, Yu M, Zhao M, Pedentchouk N, Lea-Smith DJ, Todd JD, Magill CR, Zhang W-J, Zhou S, Song D, Zhong H, Xin Y, Yu M, Tian J, Zhang X-H (2019) Proliferation of hydrocarbon degrading microbes at the bottom of the Mariana Trench. Microbiome 7:47

Machado A, Bordalo AA (2014) Diversity and dynamics of the Vibrio community in well water used for drinking in GuineaBissau (West Africa). Environ Monit Assess 186:5697-5709

Mansergh S, Zehr JP (2014) Vibrio diversity and dynamics in the Monterey Bay upwelling region. Front Microbiol 5:48

Matteucci G, Schippa S, Di Lallo G, Migliore L, Thaller MC (2015) Species diversity, spatial distribution, and virulence associated genes of culturable vibrios in a brackish coastal Mediterranean environment. Ann Microbiol 65:2311-2321

Mylroie JE, Carew JL, Moore AI (1995) Blue holes: definition and genesis. Carbonate Evaporites 10:225-233

Oberbeckmann S, Fuchs BM, Meiners M, Wichels A, Wiltshire KH, Gerdts G (2012) Seasonal dynamics and modeling of a Vibrio community in coastal waters of the North Sea. Microb Ecol 63:543-551

Plotieau T, Lavitra T, Gillan DC, Eeckhaut I (2013) Bacterial diversity of the sediments transiting through the gut of Holothuria scabra (Holothuroidea; Echinodermata). Mar Biol 160:3087-3101

Pohlman JW, Iliffe TM, Cifuentes LA (1997) A stable isotope study of organic cycling and the ecology of an anchialine cave ecosystem. Mar Ecol Prog Ser 155:17-27 
Pruzzo C, Huq A, Colwell RR, Donelli G (2005) Pathogenic Vibrio species in the marine and estuarine environment, oceans and health: pathogens in the marine environment. Springer, Boston, pp 217-252

Reen FJ, Almagro-Moreno S, Ussery D, Boyd EF (2006) The genomic code: inferring Vibrionaceae niche specialization. Nat Rev Microbiol 4:697

Sarbu SM, Kane TC, Kinkle BK (1996) A chemoautotrophically based cave ecosystem. Science 272:1953-1955

Séré MG, Tortosa P, Chabanet P, Turquet J, Quod JP, Schleyer MH (2013) Bacterial communities associated with Porites white patch syndrome (PWPS) on three Western Indian Ocean (WIO) coral reefs. PLoS One 8:e83746

Seymour J, Humphreys W, Mitchell J (2007) Stratification of the microbial community inhabiting an anchialine sinkhole. Aquat Microb Ecol 50:11-24

Siboni N, Balaraju V, Carney R, Labbate M, Seymour JR (2016) Spatiotemporal dynamics of Vibrio spp. within the Sydney Harbour Estuary. Front Microbiol 7:460

Simidu U, Tsukamoto K (1980) A method of the selective isolation and enumeration of marine Vibrionaceae. Microb Ecol 6:181-184

Svitil AL, Chadhain S, Moore JA, Kirchman DL (1997) Chitin degradation proteins produced by the marine bacterium Vibrio harveyi growing on different forms of chitin. Appl Environ Microbiol 63:408-413

Takemura AF, Chien DM, Polz MF (2014) Associations and dynamics of Vibrionaceae in the environment, from the genus to the population level. Front Microbiol 5:38

Tamaru Y, Araki T, Amagoi H, Mori H, Morishita (1995) Purification and characterization of an extracellular beta-1,4-mannanase from a marine bacterium, Vibrio sp. strain MA-138. Appl Environ Microbiol 61:4454-4458

Thompson JR, Polz MF (2006) Dynamics of Vibrio populations and their role in environmental nutrient cycling. In: Thompson WF, Austin B, Swings J (eds) The biology of vibrios. ASM Press, Washington, DC, pp 190-203

Thompson FL, Thompson CC, Hoste B, Vandemeulebroecke K, Gullian M, Swings J (2003) Vibrio fortis sp. nov. and Vibrio hepatarius sp. nov., isolated from aquatic animals and the marine environment. Int J Syst Evol Microbiol 53:1495-1501

Thompson FL, Iida T, Swings J (2004a) Biodiversity of vibrios. Microbiol Mol Biol Rev 68:403-431

Thompson JR, Randa MA, Marcelino LA, Tomita-Mitchell A, Lim E, Polz MF (2004b) Diversity and dynamics of a north Atlantic coastal Vibrio community. Appl Environ Microbiol 70:4103-4110

Turner JW, Good B, Cole D, Lipp EK (2009) Plankton composition and environmental factors contribute to Vibrio seasonality. ISME J 3:1082-1092
Unanue M, Ayo B, Azúa I, Barcina I, Iriberri J (1992) Temporal variability of attached and free-living bacteria in coastal waters. Microb Ecol 23:27-39

Venugopal M, Saramma AV (2006) Characterization of alkaline protease from Vibrio fluvialis strain VM10 isolated from a mangrove sediment sample and its application as a laundry detergent additive. Process Biochem 41:1239-1243

Wang YP, Shi XC, Zhang X-H (2015) Diversity of culturable anaerobic bacteria isolated from intertidal sediments of Qingdao (in Chinese, abstract in English). Mar Sci 39:92-97

Wang X, Liu J, Li B, Liang J, Sun H, Zhou S, Zhang X-H (2019) Spatial heterogeneity of Vibrio spp. in sediments of Chinese marginal seas. Appl Environ Microbiol 85:e03064-e03118

Westrich JR, Griffin DW, Westphal DL, Lipp EK (2018) Vibrio population dynamics in mid-Atlantic surface waters during Saharan dust events. Front Mar Sci 5:12

Whitaker F, Smart P (1990) Active circulation of saline ground waters in carbonate platforms: evidence from the Great Bahama Bank. Geology 18:200-203

Xie L, Wang B, Pu X, Xin M, He P, Li C, Wei Q, Zhang X, Li T (2019) Hydrochemical properties and chemocline of the Sansha Yongle Blue Hole in the South China Sea. Sci Total Environ 649:1281-1292

Paranjpye RN, Nilsson WB, Liermann M, Hilborn ED, George BJ, Li Q, Bill BD, Trainer VL, Strom MS, Sandifer PA (2015) Environmental influences on the seasonal distribution of Vibrio parahaemolyticus in the Pacific Northwest of the USA. FEMS Microb Ecol 91:fiv121

Yao P, Chen L, Fu L, Yang Z, Bi N, Wang L, Deng C, Zhu C (2018) Controls on vertical nutrient distributions in the Sansha Yongle Blue Hole, South China Sea (in Chinese, abstract in English). Chin Sci Bull 63:2393-2402

Yin Q, Fu B, Li B, Shi X, Inagaki F, Zhang X-H (2013) Spatial variations in microbial community composition in surface seawater from the ultra-oligotrophic center to rim of the South Pacific Gyre. PLoS One 8:e55148

Zhang L, Wang Y, Liang J, Song Q, Zhang X-H (2016) Degradation properties of various macromolecules of cultivable psychrophilic bacteria from the deep-sea water of the South Pacific Gyre. Extremophiles 20:663-671

Zhang X-H, Lin H, Wang X, Austin B (2018) Significance of Vibrio species in the marine organic carbon cycle-a review. Sci China Earth Sci 61:1357-1368

Zheng Y, Yu M, Liu J, Qiao Y, Wang L, Li Z, Zhang X-H, Yu M (2017) Bacterial community associated with healthy and diseased Pacific white shrimp (Litopenaeus vannamei) larvae and rearing water across different growth stages. Front Microbiol 8:1362

\section{Affiliations}

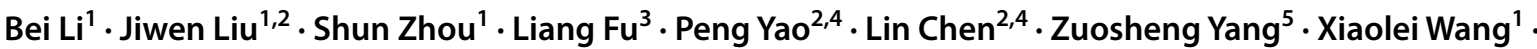 Xiao-Hua Zhang ${ }^{1,2,6}$}

1 College of Marine Life Sciences, Ocean University of China, 5 Yushan Road, Qingdao 266003, China

2 Laboratory for Marine Ecology and Environmental Science, Qingdao National Laboratory for Marine Science and Technology, Qingdao 266237, China

3 Sansha Track Ocean Coral Reef Conservation Research Institute, Sansha 573199, China

4 Key Laboratory of Marine Chemistry Theory and Technology, Ministry of Education/Institute for Advanced Ocean Study, Ocean University of China, Qingdao 266100, China

5 College of Marine Geosciences, Ocean University of China, Qingdao 266100, China

6 Institute of Evolution and Marine Biodiversity, Ocean University of China, Qingdao 266003, China 